Aug. 19ih, and the placenta at 3 P.M., 20th, being thirty-seven hours instead of thirteen. Does he consider that the use of cold, the plug, and stimulants, are an abandonment of the case to the powers of nature? I beg to refer him to my letter, "6 the hæmorrhage was arrested, and the collapse extreme;" under these circumstances I deemed manual interference to be bighly dangerous, and desperately rash and ill-advised. Note the result, " the placenta was expelled without further hæmorrhage."

2. "Is it not the duty of the practitioner, when hæmorrhage does take place, and adhesion of the placenta is known or supposed to exist, to assist nature by its removal ?"

I recommend "the Surgeon" to consult the various authorities on this point, and especially the sound precepts of the experienced and judicious, the graphic and eloquent Blundell, " a meddlesome midwifery is bad. Beware,-to disturb the clots by manual operation may be death."

The Surgeon marks the word successful by inverted commas; he aims, but strikes not. $I$ did not use it in my communication, it was thus headed by the editor; nevertheless, I venture to assert it to be, as regards transfusion, most successful and triumphant.

Should the Surgeon be disposed to offer further queries or observations, perhaps he will favour us also with his name, of which I trust he is not ashamed. I am, Sir, your obedient servant,

$$
\text { Reading, Dec. 15, } 1840 .
$$

George Miy.

\section{INCREASE OF SMALL-POX.}

\section{To the Editor of The Lancer.}

SIR :-Upon referring to the tables of mortality, I find that the number of deaths, from small-pox, in the metropolis, is still increasing; and still no efficient measures are alopted for carrying out the Vaccination Act.

The number of deaths from this disease, according to the last table, is 66 ; and supposing that 1 in 4 of those attacked with small-pox die, which used to be the calculation 30 or 40 years ago, we may conclude that 264 new cases occur weekly. As, however, in the present advanced state of medical science, the proportion of deaths is probably much less, it is likely that this calculation is much under the mark. The average length of illness in cases of smallpox is, I believe, nearly a month; but supposing it only twenty days, we shall find that there are at present in the metropolis 5280 cases of small-pox; and, according to Mr. Farr's calculation,* this number will keep on increasing for two or three ronths longer.

* See his letter in The Lancer.
What, then, are the inhabitants of London thinking about, that they allow the parish authorities to neglect the means of putting a stop to such a plague? Are they waiting to see if they can, by their neglect, drive out of town every respectable family which has not some urgent tie to bind it to the metropolis? Are the shopkeepers at the West-end of the town waiting till they see their shops crammed with goods and deserted by customers? When the loss of a single individual by such a state of things would probably amount to much more than the expense of vaccinating a whole parish. Are they aware that for half the expense of burying those who die of small-pox, raccination might be made almost universal?

It is true that some of the parish authorities have engaged medical men to attend at certain stations to vaccinate those who ap. ply to them; but it is equally certain that this will answer little purpose. The town did not want for stations for vaccinating before the passing of the Vaccination Act; but the poor are so careless and indifferent, that they will not avail themselves of these facilities. If it be considered desirable, not only for the poor, but for all persons, that vaccination should be made general, and small-pox thereby rendered extinct, persons must be employed to search out the poor and vaccinate all who will permit it. I have no doubt that in this way 19 out of 20 of the population might soon be raccinated.

Trusting, Sir, that the inhabitants of the metropolis will take this matter into their serious consideration, and for the sake of their own interest, if not for the cause of humanity, take efficient measures to put a stop to the present epidemic, I remain your most obedient servant,

Joseph Curtis.

Camden-town, Dec. 12, 1840.

\section{THE EXTENSION OF VACCINATION} ACT.

\section{To the Eaitor of THE LANCET.}

Sir :-You, doubtless, remember the occa. sion on which Esop represents one of his characters as exclaiming, "Oh! my sons, behold the power of unity." The medical men about Brentford have nobly illustrated the truth of the sage's experiment; we, too, the medical officers of the Edmonton Union, have followed in their wake : see the result; here is the brief detail.

On the 29th of October, the board directed their medical officers to be written to, to ascertain whether they were willing to vaccinate in their several districts, according to the new Act, at 1s.6d. per case. A meeting of six of the medical staff of seven took 
place; we answered the board by declining to enter on the provision of the new Act at less than 2s. 6. $\mathrm{d}$. per case. It was late before our joint tender was sent in, scarcely more than one-tenth of the guardians were present; we had not expected any decision till the next board-ciay, yet this fraction, considering that as medical men had generally vaccinated gratuitously, and as we "had vaccination included under our present contract," resolved that 1 s. 6d. was a sufficient remuneration, and again offered the said sum.

The only surgeon who did not attend the meeting of his confrères, accepted the $13.6 \mathrm{~d}$.

The six non-contents, however, met again; urged the attendance of a full board; renewed their application for the half-crown. At the next board-day they were warmly seconded by the more liberal guardians, and had the gratitication of carrying the halfcrown by a majority of fifteen to nine.

A guardian proposed that the seceder be promoted to the level of his half-crown brethren; the board resolved accordingly. It is but justice, however, to this gentleman to remark, that he has to-day coalesced with us, from whom he so injudiciously sepa. rated, owing, it appears, to some erroneous notion he entertained that paupers only could be vaccinated under the new Act. He has, with much good feeling, withdrawn his original tender of 1s. 6d., and now, with us, refuses to accept the same, even should the commissioners decline to confirm the halfcrown appointment.

We wait their decision; but we have thought it well to put on record, and circulate as soon as may be, the above detail, that other surgeons, situated as we were, may be like-minded; and feel, when impelled by a sense of what is due to themselves and their profession, that they are not travelling allogether a "terra incognita," or destitute of the chart and compass of other men's experience. I am, Sir, on behalf of my colleagues, the medical officers of the Edmonton Union, your very obedient servant,

Charles F. J. Lord.

Hampstead, Nov. 25.

\section{COERCION OF THE INSANE.}

REPLY OF "A LOOKER-ON" TO MR. STILWELL AND DR. BLAKE.

\section{To the Editor of THE Lancet.}

SIR:-Let me put myself right with Mr. Stilwell. I had no intention of charging him with having, at any time, adrocated the "system of cocrcion, in its ordinary sense :" I used the word abandon in an argumentative sense ouly. He asks my opinion of the treatment used "in the extraordinary case" No. 904. he narrates. I can only say, may such $e x$ traordinary cases and such extraordinary restraints increase and multiply. If restraints are to be so reduced in strength, and so accompanied with kind treatment, and reserved for such cases, the controversy will soon become a mere war of words.

"Philalethes" is a naughty boy, and must be rebuked. $\mathrm{He}$ is too dogmatical in his arguments. I cannot go through all his dogmas ; but I will expose one. "The pa. tient who would swallow his own ordure, must be forcibiy prevented." Must he, good "Philaletnes?" Do you not know, that patients will eat their ordure, though subject to the severest restraints? But read what Dr. Conolly says on this subject:-

"Patients will sometimes swallow any kind of dirt and nastiness. Amidst the numerous and obvious means of preventing this, the attendants never think of any but one; and that is, restraint. Deny them the strait-waistcoat, and they let such cases take their chance. No decent precaution, no at tempt to encourage cleanliness, no device for obviating what is disgusting, presents itself to their minds; and a disposition may exist to represent such cases as illustrations of the wildness of the attempt to banish bodily coercion. In some very recent instances in this asylum, supplying these unhappy patients with a little bread at bed. time, was resorted to by the resident physician; and the patients have since been reported as having relinquished the practice, previously represented in a manner to give him the greatest uneasiness."

Which of the twain, "Philalethes," is the more "beneficent restraint," the straitwaistcoat or the piece of bread?

Dr. Blake surprises me. I wish he would get out of the Lincoln atmosphere, and not join in the cry against Mr. Hill, who seems to have roused a jealousy in that neighbourhood, because he has ventured, as a young man, to give a lecture on insanity, which nothing will allay. I can only tell $\mathrm{Dr}$. Blake, that if he can entirely abolish restraint in the old part of the Nottingham Asylum, he will demonstrate, beyond controversy, that Mr. Hill is wrong in his position, that "a properly-construeted building" is required for such porpose. I would further ask of Dr. Blake, although be will not offer a decided opinion on the important question, "Whether the nervous energy is not sooner exhausted, and the paroxysms shortened, by seclusion?" if he could not give a remarkable instance, from his own asylum, where the two methods of restraint and seclusion have been tried on the same patient? His cases, illustrative of the necessity of restraint, answer themselves. I am, Sir, your obedient servant,

A LOORER-ON,
Dec. 22,1840 . 